\title{
Evaluation of Two Facial Nerve Landmarks Frequency in Parotidectomy
}

\author{
Ahmadreza Okhovvat ${ }^{1}$, Maryam Yaghoubi Hamgini ${ }^{2 *}$, Seyed Mostafa Hashemi ${ }^{1}$, Seyed Hamidreza Abtahi ${ }^{1}$ \\ ${ }^{1} \mathrm{MD}$, Associate Professor of Otorhinolaryngology, Ayatollah Kashani Hospital, Isfahan University of Medical Sciences, Isfahan, Iran \\ ${ }^{2} \mathrm{MD}$, Otorhinolaryngologist, Ayatollah Kashani Hospital, Isfahan University of Medical Sciences, Isfahan, Iran \\ * Corresponding Author Address: Department of Otorhinolaryngology, Alzahra Hospital, Isfahan, Iran. Tel:+989132883763. \\ Email: ghazalmm2050@gmail.com
}

Article Type: Research Article

Received: October 15, 2016, Last Revised: December 28, 2016, Accepted: December 30, 2016, Published: March 30, 2017

\section{Abstract}

Background \& Aim: Various landmarks are discussed to find the facial nerve during parotid surgery. The surgeon should use existing landmarks for a safe surgical use. To evaluate two new landmarks in parotid surgery, this study was done.

Methods \& Materials/Patients: This cross-sectional study was conducted on 43 patients with parotid masses, whom were referred to Alzahra and Kashani tertiary hospitals in 2013. In a parotid surgery, the greater auricular nerve was detected; then the greater auricular nerve and facial nerve diameter were measured by the compass with precision of 0.1 millimeter and recorded. After facial nerve exploration, if the other landmarks of vascular and tail signs are detected, they are recorded in the files.

Results: This study contained 43 patients, 22 men and 21 women. There were $21(48.8 \%)$ masses in deep lobes and others on superficial lobes. In 36 cases $(83.7 \%)$, vascular signs were observed. In 23 cases $(53.5 \%)$, tail signs were found. The diameter of facial nerve was $2.647( \pm 4641) \mathrm{mm}$ (minimum: $2 \mathrm{~mm}$ and maximum: $4 \mathrm{~mm}$ ). The diameter of greater auricular nerve was 2.691 $( \pm 4545) \mathrm{mm}$ (minimum: $2 \mathrm{~mm}$ and maximum: $4 \mathrm{~mm}$ ). By paired T-test, there was no significant difference between the diameter of facial and greater auricular nerves. Of all cases, $76.7 \%$ had differences less than $0.5 \mathrm{~mm}$.

Conclusion: This study showed that greater auricular nerve can be used as a proper graft for facial nerve, and we can use "vascular sign" as a good indicator of facial nerve.

Keywords: Parotid Surgery, Facial Nerve, Greater Auricular Nerve, Vascular Sign, Tail Sign, Complication

Please cite this paper as: Okhovvat A, Yaghoubi Hamgini M, Hashemi SM, Abtahi SH. Evaluation of Two Facial Nerve Landmarks Frequency in Parotidectomy. Iran. J. Neurosurg. 2017;2(4):6-8

\section{Introduction}

Parotid gland is the largest salivary gland, which lies beside masseter and sternocleidomastoid muscles [1]. Generally, salivary gland tumors are rare neoplasms and consist about $3-4 \%$ of the head and neck tumors [3]. Their average annual incidence is 7.4 per hundred thousand for benign tumors, and for malignant tumors is 0.9 per hundred thousand [2]. Of these, about $80 \%$ of salivary gland tumors occur in parotid, and approximately $70-75 \%$ of the parotid tumors are benign [1]. The recommended treatment for benign tumors of the salivary glands is complete resection with surgical margins. With complete resection of the tumor and the tumor sections involved, the prognosis is excellent. Usually a superficial parotidectomy with facial nerve preservation is sufficient, unless there is a deep lobe involvement. Several structures pass through the parotid gland and are of considerable surgical importance; the facial nerve is the most important among these structures [1].

Facial nerve comes out from the skull base and passes beneath the ear, passes through the parotid gland and divides it into superficial and deep lobes [4]. Risky course of the facial nerve within the parotid gland makes it susceptible to considerable damage risk during parotid surgery [4,5,7,12-15]. Among the most common complications are temporary facial nerve pareses following parotid surgery especially marginal mandibular branch [2].

Cross section of each of the branches leads to paralysis of the facial nerve innervation of the contributed muscles [6]. The incidence of early facial nerve paresis after parotidectomy is about $46 \%$, that permanent paralysis is uncommon and about 4\% [6]. Therefore, it is necessary to identify the course of facial nerve during parotid surgery [8]. Knowledge of the key landmarks of the facial nerve trunk in parotid gland is essential for a safe and effective surgical intervention [9].

In this context, several landmarks have been discovered and used [8]. Key landmarks to identify the facial nerve are tragal pointer, the tip of the mastoid, posterior belly of digastric muscle, tympanomastoid suture and styloid process $[6,10,17]$.

The results of one study have shown that posterior belly of digastric muscle, tragal pointer, and transverse processes of axis are fixed landmarks of the facial nerve trunk [8]. The surgeon should consider the safe possible 
surgical landmarks to perform a safe surgery [11].

Due to the stressful nature of the surgery and possible facial nerve injury and so many problems of facial nerve and subsequent paralysis of the nerve receptors and muscle paralysis and their impact on the quality of life of patients and presence of evidence in small number of previous studies, this research investigated two new landmarks in parotid surgery.

\section{Methods and Materials/Patients}

This cross-sectional study was conducted on 43 patients with parotid masses, whom were referred to Alzahra and Kashani tertiary hospitals in 2013-14, and parotid surgery was performed. All of the patients gave informed written consent to participate in the study. The study was approved by the Research Ethics Board of Isfahan University of Medical Sciences, and performed in accordance with the 1964 Declaration of Helsinki.

In the parotid surgery, after the incision of platysma muscle in the vicinity of the Erb's point, the greater auricular nerve was detected; then the trunk of greater auricular nerve and facial nerve diameter were measured by the compass with precision of 0.1 millimeter and recorded. Facial nerve diameter was measured just before its bifurcation. After facial nerve exploration, if the other landmarks of vascular and tail signs are detected, they are recorded in the files.

The main aim of this study was evaluation of two new landmarks in parotid surgery. These two landmarks were: 1-"Tail sign ":a part of the superficial lobe of the parotid gland just before the entrance to the facial nerve trunk as a tail-like appendages on the trunk of the facial nerve has been developed, that we examined the prevalence of this sign in the patients. 2-"Vascular sign": evaluation of the presence of a blood vessel in correlation with facial nerve; that are posterior auricular artery and its branches in the relation to facial nerve just before the entrance to the facial nerve [18]. Other aims of this study were determination of the frequency of deep lobe of parotid tumors, and the difference between the diameters of the facial nerve and the greater auricular nerve.

After data collection, the data were entered into SPSS version 19. To determine the prevalence of landmarks such as vascular sign, tail sign and the diameter of the facial nerve to greater auricular nerve, McNemar's test and paired T-test and T-test were used.

\section{Results}

This study contained 43 patients, 22 men and 21 women. There were $21(48.8 \%)$ masses in deep lobes and others on superficial lobes.

By independent T-test, there were no significant differences between male and female diameters of facial nerves $(p=0.39)$ and greater auricular nerves $(p=0.94)$.

In 36 cases $(83.7 \%)$, "vascular signs" were observed. In 23 cases $(53.5 \%)$, "tail signs" were found. Mc-Nemar's test has shown significant difference between prevalence of vascular sign and tail sign $(\mathrm{p}=0.004)$.

The diameter of facial nerve was $2.647( \pm 4641) \mathrm{mm}$ (range: $2-4 \mathrm{~mm}$ ). The diameter of greater auricular nerve was 2.691 $( \pm 4545) \mathrm{mm}$. (range: $2-4 \mathrm{~mm})$. By paired T-test, there was no significant difference between the diameter of facial and greater auricular nerves.

The mean difference between facial and greater auricular nerve is described in table 1 . This difference had no significance in both genders $(p=0.92)$.
Table 1. Diameters of Facial and Greater Auricular Nerves and their Difference in Males and Females

\begin{tabular}{|c|c|c|c|}
\hline & $\begin{array}{c}\text { Male } \\
(\text { mean } \pm \text { SD })\end{array}$ & $\begin{array}{c}\text { Female } \\
(\text { mean } \pm \text { SD })\end{array}$ & P-value \\
\hline Facial Nerve & $2.59 \pm 0.09$ & $2.77 \pm 0.11$ & 0.39 \\
\hline $\begin{array}{c}\text { Greater } \\
\text { Auricular Nerve }\end{array}$ & $2.69 \pm 0.07$ & $2.68 \pm 0.12$ & 0.94 \\
\hline $\begin{array}{c}\text { Difference } \\
\text { between } \\
\text { Facial Nerve } \\
\text { and Greater } \\
\text { Auricular Nerve }\end{array}$ & $0.36 \pm 0.08$ & $0.38 \pm 0.09$ & 0.92 \\
\hline
\end{tabular}

\section{Discussion}

This study has shown that there is a relative proportion between facial and greater auricular nerve, and $76.7 \%$ of cases had differences less than $0.5 \mathrm{~mm}$ that simplifies the grafting of greater auricular nerve as a substitution of facial nerve. Mokhtari et al. reported 300 parotid surgery during 20 years in Ghom and Mashhad, Iran; they found that 12 patients $(4 \%)$ needed to repair nerve because of damage to the facial nerve during surgery [3]. Our study has shown the minimal differences of facial and greater auricular nerves, so these cases can be repaired by greater auricular nerve grafting. Pereira JA, et al, studied 79 cadavers in a retrospective study in 2004 in the Department of Anatomy, University Hospital, Barcelona. They made a three $\mathrm{cm}$ incision in the lower center of the triangle, between the temporomandibular joint, and the angle of the mandible and the mastoid process, and then went so deep part to reach the trunk of the facial nerve, then they measured the distance between predicted site to nerve trunk that had an average of 1.42 $\mathrm{mm}$; they found that proposed landmarks allow faster and safer approaches to identify the facial nerve [16].

In a study by Upile and colleagues, stylomastoid artery is similar to our "vascular sign". They consistently identified a supplying vessel, stylomastoid artery, and they believed that this artery tends to vary less in position than the facial nerve; and a few millimetres inferiorly and medially, they had gone on to identify the facial nerve trunk, with relative ease. They thought that the origin of the stylomastoid artery can be either from the occipital artery or the posterior auricular artery [18].

Pather N, et al in 2006 at the University of Witwatersrand in South Africa studied 40 adult cadavers; and they evaluated the transverse processes of the vertebrae, because it is easily palpable, and there is no need to extensive incision, and risk of injury to the facial nerve trunk is lower [9].

Greyling LM in a study in 2007 in the Department of Anatomy, University of Pretoria, South Africa, studied 40 cadavers. They proposed two bony landmarks for facial nerve: the tip of the mastoid process and midpoint of transverse process of the atlas. The distances were measured on both sides. The mean distance between the mastoid process to the nerve trunk was $9.18 \pm 2.05 \mathrm{~mm}$ at the left side and $9.35 \pm 1.67 \mathrm{~mm}$ at the right side. The distance between atlas and the nerve trunk was $14.31 \pm 3.59 \mathrm{~mm}$ at the left and $13.76 \pm 4.65 \mathrm{~mm}$ at the right side. They found that risk of injury to the facial nerve trunk can be minimized by the data obtained of these landmarks, but the clinical studies for the application of this landmarks are required [8]. 


\section{Conclusion}

Our study discussed two indicators of parotid surgery, and more studies in this context is helpful for a safe and better surgeries of facial nerves in future. Further studies are required to determine the distance between the artery of vascular sign and tail like appendage (tail sign) to facial nerve.

\section{Funding}

none.

\section{Conflicts of Interest}

The authors declare that they have no conflicts of interest.

\section{Authors' Contribution}

Conception and Design: All authors.

Data Collection: All authors

Drafting the Article: All authors

Critically Revising the Article: All authors

Reviewing Submitted Version of Manuscript: All authors Approving the Final Version of the Manuscript: All authors.

\section{References}

1. Lalwani AK. Current diagnosis \& treatment in otolaryngology: McGraw-Hill Medical; 2008.

2. Khajavi M, Peyvandi AA, Naghibzadeh B, Ahmadi RoozbahaniN. Salivary Gland Tumors in Patients Referring to Loghman Hakim Hospital in a 10-Year Period. Pejouhandeh Research Journal. 2010;15 (1): 45-48.

3. Mokhtari N, Majdi A, Pourhamzeh M. Surgical dissection of the facial nerve in parotidectomy. Iran J Otorhinolaryngol.. 2010; 22: 60-64.

4. Rahman MA, Alam MM, Joarder AH. Study of nerve injury in parotid gland surgery. Nepalese journal of ENT Head \& Neck Surgery. 2011; 2: 16-18.

5. Ragona M, Filippis C, Marioni G, Staffieri A. Treatment of complications of parotid gland surgery. ActaOtorhinolaryngol Ital. 2005 June; 25(3): 174-178. 6. Flint PW, Haughey BH, Robbins KT, Thomas JR, Niparko JK, Lund VJ, Lesperance MM. Cummings otolaryngology-head and neck surgery. Elsevier Health Sciences; 2010, 5th ed. Vo12.

7. Guntinas-Lichius 0, Gabriel B, Klussmann JP. Risk of facial palsy and severe Frey's syndrome after conservative parotidectomy for benign disease: analysis of 610 operations. Acta Otolaryngol. 2006 Oct; 126(10): 1104-9.

8. Greyling LM, Glanvill R, Boon JM, Schabort D, Meiring JH, Pretorius Jp, van Schoor A. Bony landmarks as an aid for intraoperative facial nerve identification. Clin Anat. 2007 Oct; 20(7):739-44.

9. Pather N, Osman M. Landmarks of the facial nerve: implications for parotidectomy SurgRadiol Anat. 2006 May;28(2): 170-5.

10. Bailey B, Calhoun K, Friedman N, Newlands Sh, Vrabec J. Atlas of Head \& Neck Surgery Otolaryngology. 2th. Philadelphia: Lippincott Williams \& Wilkins; 2001.

11.Wetmore SJ. Surgical landmarks for the facial nerve. OtolaryngolClin North Am. 1991 Jun; 24(3):505-30.

12. ArabiMianroodi A, Jorjandi M. The Epidemiology of Parotid Tumors at the Ear, Nose and Throat Department of Shafa Educational Hospital, Kerman, Iran.2012;3(1):174-180.

13. Berjis N, Okhovat A, Baluchi M, Okhovat H. Complications and recurrence of parotid pleomorphic adenoma after partial parotidectomy at Alzahra hospital. JRMS. 2007; 12(1): 38-40.

14. Weerapant E, Bunaprasert T, Chokrungvaranont P, Chentanez V. Anatomy of the facial nerve branching patterns, the marginal mandibular branch and its extraparotid ramification in relation to the lateral palpebral line. Asian Biomed. 2010; 4: 6033608

15. Klintworth N, Zenk J, Koch M, Ira H. Postoperative Complications After Extracapsular Dissection of Benign Parotid Lesions With Particular Reference to Facial Nerve Function. The Laryngoscope. 2010; 120: 484-490.

16. Pereira JA, Meri A, Pota.u JM, Prats-Galino A, Sancho JJ, Sitges-Serra: A. A simple method for safe identification of the facial nerve using palpable landmarks. Arch Surg. 2004 Jul; 139(7):745-7.

17. Saha S, Pal S, Sengupta M, Chowdhury K, Saha VP, MondalL.Identification of facial nerve during parotidectomy: a combined anatomical \& surgical study. Indian J Otolaryngol Head Neck Surg. 2014 Jan;66(1):63-8.

18. Upile T, Jerjes W, Nouraei SA, Singh SU, Kafas P, Sandison A, Sudhoff H, Hopper C. The stylomastoid artery as an anatomical landmark to the facial nerve during parotid surgery: a clinico-anatomic study. World J SurgOncol. 2009 Sep $28 ; 7: 71$.

\section{Comments}

The authors reported the usefulness of two new landmarks for finding the facial nerve during parotid surgery. It is well known the importance of a safe and quickly detection of the facial nerve in this type of surgery. These two new landmarks and the knowledge of the possibility of using the great auricular nerve to repair an involuntary facial injury will help surgeons to avoid any nervous damage for seeking the best outcome. 